\title{
Sobre o conceito do "Direito Social"
}

\section{Cesarino Júnior}

\begin{abstract}
"L'observation des réalités nous permettra de doter ainsi, d'une contribution empirique, l'étude des sources du droit et cette contribution favorisera peut-être le rendement des controverses qui s'appuient uniquement sur la théorie du droit".
\end{abstract}

(Hugo Sinzheimer, "La Théorie des Sources du Droit et le Droit Ouvrier", in "Le Problème des Sources du Droit Positif", pg. 73).

1 - O conceito de Direito Social que formulámos em artigo para a REVISTA DA FACULDADE DE DIREITO, (1) de São Paulo, e transcrevemos em nosso livro, "Direito Social Brasileiro" (2) suscitou várias críticas, na maioria partidas de confrades nossos do Instituto de Direito Social, e algumas publicadas em jornais (3). E' nosso desejo, neste artigo, como prova da consideração em que temos os emi-

(1) "Direito Social: denominação, conceito e conteudo", no fasc. I do vol. XXXV, de janeiro-abril, de 1939 , pgs. 214-244, publicado tambem na "Revista de Direito do Trabalho", de Recife, fasc. 11 , de janeiro de 1940 , pgs. 161 a 171 .

(2) Edição da Livraria Martins, de São Paulo, 1940, pgs. 1 a 34.

(3) R. SAbota DE Medeiros, "Realidade e Eficiencia do Direito Social", no "Jornal do Comercio", de 14 de janeiro de 1940, pg. 3; VASco DE ANDRAde, "Sinopse do "Novum Jus" (Conceituação e conteudo do Direito Social), no mesmo jornal, de 10 de março de 1940, pg. 7. Ainda sobre o nosso citado livro, cf. Sinval Palmeira, "Direito Social Brasileiro" (À margem de um livro do Prof. Ciesarino Junior), in "Forum" (Revista do Instituto da Ordem dos Advogados da Baía), fasc. 3 , do vol. XII, de 1940, pgs. 419 a 424 , e em "Inapiários", (Orgão dos Funcionários do Instituto de Aposentadorias e Pensões dos Industriários), n. 24, de abril de 1940, pgs. 10 
nentes críticos, e, satisfazendo assim prazenteiramente o nosso desejo de vêr a questão amplamente examinada, elucidar alguns pontos que nos parecem ter sido mal compreendidos e, ao mesmo tempo, precisar certas afirmações, examinando ainda os vários conceitos propostos para o Direito Social ao nosso Instituto.

2 - Definindo, como definimos, o Direito Social "o complexo de princípios e leis imperativas, cujo objetivo é, tendo em vista o bem comum, auxiliar a satisfazer convenientemente às necessidades vitais próprias e de suas familias, aos indivíduos para tanto dependentes do produto do seu trabalho", tivemos tão sómente em mira formular um conceito rigorosamente científico, partindo da observação das chamadas "leis sociais", isto é, seguindo um critério objetivo, baseando-nos em dados de fatos positivos. Não foi nossa intenção alçar-nos a um ponto de vista filosófico, o que, entretanto, foi feito por numerosos outros autores que se ocuparam do assunto.

Com efeito, do ponto de vista da Filosofia do Direito, o Direito Social não seria apenas o definido por nós. Com justa razão assinalou RADBRUch (4), a passagem de uma con-

e 11; Mariano R. Tissembaum, "Direito Social Brasileiro", no "Boletim do Instituto de Derecho del Trabajo", de Santa Fé, Republica Argentina, Tomo I, de 1940, pgs. 82 a 92; Plinio Barreto, "Direito Social Brasileiro", no "Estado de São Paulo", de 1 de março de 1940, e na "Folha da Manhã", de Recife, de 7 de março de 1940, pg. 7; Fernando Callage, "Direito Social Brasileiro", no "Correio Paulistano", de 6 de dezembro de 1939; "Direito Social Brasileiro", editorial da revista "Legislação do Trabalho", vol. III, pg. 503; "Legislação do Trabalho", editorial do "Correio Paulistano", de 9 de dezembro de 1939; "Direito Social Brasileiro", editorial da "Justiça do Trabalho", de novembro-dezembro de 1939, pg. 2; "Direito Social Brasileiro", editorial da "Revista do Trabalho", de dezembro de 1939, pg. 11; "Direito Social Brasileiro", editorial da "A Gazeta", de São Paulo, de 3 de março de 1940; A. B. Cotrim Neto, Direito Social Brasileiro, in "I. A. P. C.", revista do Instituto de Aposentadoria e Pensões dos Comerciarios, n. de setembro de 1940, pg. 81; "Vozes de Petropolis", n. de outubro de 1940, pg. 600; Amaury PEDhosa, Direilo Social Brasileiro, in "Legislação do Trabalho", n. de novembro de 1940 , pgs. 421 a 427 .

(4) "Du Droit Individualiste au Droit Social", in "Archives de Philosophie du Droit et de Sociologie Juridique", ns. 3-4, de 1931, pgs. 387-398. 
cepção individualista do mundo, a uma concepção "social", por efeito de revoluçóes econômicas. 0 direito social, lato sensu, se carateriza pelo fato de considerar o "homem concreto e socializado" e não apenas o "indivíduo despersonalizado e abstrato", de acôrdo com a concepção individualista. "Cette conception se exprimait par la notion juridique de la personne. Cette notion de personne est un concept d'uniformité, en lui sont nivelées toutes les differences des hommes: est également une personne celui qui possède et celui qui ne possède rien, le faible particulier et l'association personalisée à la force du mammouth. Dans le concept de personne sont pensées d'égalité juridique, l'égale liberté de disposer de la proprieté, et l'égale liberté de contrat, pour tous. Mais, dans la réalité du droit, la liberté de proprieté et de contrat est, entre les mains de celui qui est puissant socialement, quelque chose d'essentiellement differente de ce qu'elle est entre les mains du socialement faible. La liberté du possédant devient, de liberté de disposer des choses, liberté de disposer des hommes: celui qui est maître des instruments de travail a aussi puissance commandante sur les travailleurs". (5) E assim, "la liberté juridique du contrat devient, dans la réalité sociale, la liberté de dictadure de celui qui est socialement puissant, l'asservissement de celui qui est socialement faible". E' esta mesma a preocupação dos juristas católicos ao falarem em direitos da "pessoa humana". E, por "homem concreto e socializado", devemos entender o homem tambem como membro dos "grupos" sociais : sindicatos, corporações, igrejas, universidades, etc. Efetivamente, afirma o citado RADBRUCH, numa outra obra: "Se quiséssemos traduzir em linguagem jurídica a enorme revolução que estamos presenciando nos fatos e nas idéias, diríamos que a tendência para um "Direito Social", cada vez mais vai socavando a separação rígida entre Direito Privado e Direito Público, entre Direito Civil e Direito Administrativo, entre contrato e lei: ambos os tipos de Direito penetram um no outro reciprocamente, dando lugar à apa-

(5) Ob. cit., pg. 389 . 
rição de novos campos jurídicos, que não podem ser atribuidos, nem ao Direito público, nem ao privado, senão que representam um Direito inteiramente novo, de um terceiro tipo: o Direito econômico e operário". (6) E acrescenta: " $\mathrm{E}$ ' discutivel si o direito econômico é um novo ramo jurídico ou apenas um novo método do pensamento jurídico, aplicavel aos seus mais variados campos. Pelo contrário, - Dineito operário constitue uma disciplina nova. Enquanto o Direito econômico considera as relações econômicas do ponto de vista da produtividade, o Direito operário as focaliza segundo o critério da proteção do debil perante o poderoso endinheirado. $\mathrm{O}$ primeiro se inclina mais para o ponto de vista do empresário; o segundo, preponderantemente para o interesse do operário. Daí, entrarem em luta, como na questão do dia de oito horas. O Direito Operário é uma reação contra o espírito do Direito Civil. Este reconhece só "pessoas", sujeitos jurídicos, que contratam entre si mediante livres decisões de ambas as partes; e nada sabe do trabalhador, situado numa posição de inferioridade perante o empresário. Nada sabe tambem da solidariedade do proletariado, que compara ou nivela esta inferioridade do poder do operário individual perante o patrão; nem das grandes associações profissionais que mediante seus contratos coletivos de trabalho, são quem propriamente os conclue, senão que mira exclusivamente aos contratantes individuais e ao contrato de trabalho singular. Nada sabe, por fim, da unidade de trabalho da empresa. A essêncià do Direito operário, consiste, cabalmente, em sua maior proximidade à vida... Não vê só pessoas, como o Direito Givil, senão empresários, operários, empregados; não só pessoas individuais, senão associações e empresas; não só contratos livres, senão tambem as grandes lutas econômicas que constituem o fundo destes supostos contratos livres".

3 - Além deste primeiro caraterístico do Direito Social lato sensu, de fazer aparecer por trás da abstração ni-

(6) "Introducion a la Ciencia de Derecho", Madrid, 1930, pg. 108 . 
veladora do conceito de pessoa, a individualidade concreta, o estado de potência ou de fraqueza social, ha um outro muito bem expresso por LE Fur. (7) E' o de que o Direito Social resulta em regra, de uma fonte dc direito diversa da vontade do Estado (lei) e da do indivíduo (contrato). Já o haviam proclamado, com maior ou menor aproximação da verdade diversas teorias modernas, como as de Duguit (8) ("ato-regra") Hauriou e Renard (9) ("instituição") e GuRvitch ("fatos normativos"). (10)

Entretanto, dissemos, resulta, "em regra". De fato e a expressão é de Sinzzheimer (11) - esse direito "não estatal", pelo menos no que se refere ao impropriamente chamado "direito operário", não prescinde sempre da intervenção do Estado. Si é verdade que o Estado não cria os regulamentos de oficina, os contratos coletivos de trabalho, as comunidades de trabalho, mas que apenas "il les constate comme des "données", comme des "institutions", comme des "faits normatifs", (12)" por outro lado, não é menos exáto que o Estado: "intervient dans le droit non étatique pour l'impregner d'élements formels; c'est ce qui s'est produit, par exemple, dans la legislation sur les conventions colletives de travail. Il lutte, ensuite, contre les excès naissant, dans le droit extraétatique de la prédominance unilatérale des partis; exemple: protection légale des travailleurs par l'ḱtat. Il peut, enfin, contribuer à developper, par son intervention, de nouvelles formations juridiques contenues en germe dans le droit non-étatique; exemple:

(7) "Droit Individuel et Droit Social", nos citados "Archives", pgs. 279-309.

(8) "Traité de Droit Constitutionnel", tomo I, pgs. 515-516.

(9) Maurice Hauriou, "Principes de Droit Public", 2.a edição, pg. 280; Georges Renard, "La Philosophie de l'Institution", Paris, 1939, pgs. 249 a 279.

(10) "L’idée du droit social", pg. 32.

(11) "La Théorie des Sources du Droit et le Droit Ouvrier", in "Le Problème des Sources du Droit Positif", pgs. 73-81.

(12) Ob. cit., pg. 77. Sinzheimer se refere aí à doutrina de GEnx, do "donné" e do "construit" (Cf. "Science et Technique en Droit privé positif", tomo II, pg. 381). 
l'occasion manquée par l'État en Allemagne, à l'époque où les forces extra-étatiques ébauchèrent des communautés nouvelles, sans avoir la vigueur et le desintéréssement suffisants pour les achever". (13)

4 - Ora, este Direito Social, concebido como o conjunto de normas juridicas, predominantemente não-estatais, que encaram o homem em sua realidade concreta e como membro dos grupos sociais, tem evidentemente uma grande extensão. O citado RADBRUGH, conforme vimos, considera a existência, dentro dele, de apenas um ramo do direito verdadeiramente autônomo, e que é o que ele denomina "Direito Operário" e nós denominamos "Direito Social" stricto sensu, considerando o Direito Econômico antes como "um novo método do pensamento jurídico, aplicavel a seus mais vários campos" (14). Mas, é ele mesmo quem, no primeiro trabalho citado, depois de repetir que "cette époque se marque par le passage d'un âge individualiste à un âge social", afirma: "Mais, cette évolution vers le droit social, nous ne la saisissons pas dans toute sa profondeur lorsque, sous le terme de droit social, nous comprenons simplement un droit qui pourvoit à la sécurité et au salut de ceux qui sont économiquement faibles. Le droit social repose bien plutôt sur une modification structurale de toute la pensée juridique, sur une nouvelle conception de l'homme; le droit social est un droit qui s'adresse, non à l'individu sans individualité, dépouillé de sa spécificité, non à l'individu consideré comme isolé et dissocié, mais à l'homme concret et socialisé" (15). E assim mostra ele como esta preocupação com o "homem concreto e socializado", que é mais acentuada no que ele chama o Direito Operário e mesmo no Direito Econômico (16) se en-

(13) Ibidem, pg. 78.

(14) Cit. "Introducion a la Ciencia del Derecho", pg. 113.

(15) Cit. "Du Droit Individualiste au Droit Social", pg. 388.

(16) Em nosso artigo citado já o haviamos ressaltado: "E' que, a-pesar-do sentido social, da "humanização do Direito" ser comum a todos os seus ramos, êsse sentido social se acentuou sobremodo, diriamos até, se concentrou, neste ramo dos conbecimentos 
contra em todos os ramos do Direito, mesmo naqueles que até ha pouco pareciam domínio exclusivo do Direito individualista: o direito civil e o direito comercial. Assim é que, depois de mostrar a quadrupla significação da idéia do direito social: a) fazer aparecer a individualidade concreta, o estado de fraqueza ou de potencia social; b) proteger os fracos e limitar os excessos de potência social; $c$ ) fazer surgir em todas as relações jurídicas, como terceira e principal parte, a Sociedade, o Estado pronto a intervir; d) restabelecer sobre um novo terreno o acôrdo da fórma e da realidade jurídicas, mostra a sua influência no direito privado, como no público. No direito comercial, ha por exemplo o fenômeno da institucionalização das sociedades anônimas, (17) no direito de família, a modificação dos conceitos de pátrio poder e de poder marital, embora, neste domínio, certas modificações do direito aparentem efetuar uma dissolução dos liames sociais da família (plena igualdade de direito entre os esposos, facilitação do divórcio, igualdade de tratamento para os filhos legítimos e ilegítimos, na abolição dos fideicomissos familiares e na luta contra o direito ilimitado de herança dos parentes em favor de um direito de herança da comuna ou do Estado), transformando o estado de familia numa relação contratual duravel conforme a vontade dos contratantes, (18) o que, para RADBRUch, é uma revelação da tendência do direito social de adatar a fórma jurídica à realidade social. Da mesma fórma vê ele um deslocamento do direito de educação do pátrio poder à comunidade estatal nas leis de proteção à infância (19). Abstraindo do Direito

jurídicos a que uns chamam Legislação e outros, melhormente, $D i$ reito Social" (Cf. "Direito Social Brasileiro", pg. 5).

(17) Cf. Galllard, "La Societé Anonyme de Demain" (La Theorie Institutionnelle et le Fonctionnement de la Societé Anonyme), Paris, pgs. 33 e segs.

(18) Isto não é verdade para nós, pois o art. 124 pr. da Constituição afirma: "A família constituida pelo casamento indissoluvel está sob a proteção especial do Estado". Note-se que RadBruch escreve tendo em vista o direito alemão.

(19) 0 art. 125 da nossa Constituição: "A educação integral da prole é o primeiro dever e o direito natural dos pais. O Estado não será estranho a esse dever, colaborando de maneira principal 
Operário e do Direito Econômico, considerados à parte, vemos o direito penal considerar o homem concreto com sua "individualidade psicológica e sociológica" mercê da fórmula: "não o criminoso, mas o homem", refletindo-se ela no direito judiciário penal, cuja finalidade não é mais decidir sobre a culpabilidade do criminoso, mas desenhar-lhe a imagem. Igualmente no processo civil o juiz abandona a sua atitude passiva, sendo como disse Franz KLein a essência do "processo civil social", reforçar o poder do juiz em relação às partes e a seus advogados, instituir no processo a supremacia e a responsabilidade do juiz (20). Da mesma forma, na organização judiciária, em lugar dos jurados, "cidadãos abstratos", surgem os assessores dos tribunais do trabalho, que intervêm no processo como empresário, empregado, operário ou sindicalizado. No direito público, a democracia, enquanto por um lado "aparece como um edifício enorme formado dos diferentes quadros possantes que são os grupos, as classes e os partidos", (21) por outro lado "a nova ideologia está prestes a conceber a democracia como uma escola "d'élites" (leviders), como uma aristocracia organizada, ela considera 0 "leader" com seu sequito, não mais o indivíduo isolado, como elemento constitutivo da nação".

Verifica-se, assim, que, além do direito chamado operário e do direito econômico, tambem os demais ramos do direito se deixam penetrar por este sentido social, que RIPERT chamaria antes a moralização do direito, como de-

ou subsidiária, para facilitar a sua execução ou suprir as deficiências e lacunas da educação particular" é evidentemente inspirado no art. 120 da Constituição de Weimar, que declara o direito de educação: "o dever mais alto e o direito natural dos pais, sobre cujo cumprimento vela a comunidade estatal", sobre o qual baseou o nosso autor a sua afirmação.

(20) Apud Radbruch, cit. "Du Droit Individualiste au Droit Social", pg. 396.

(21) Convem lembrar aqui que o Código Eleitoral Brasileiro, promulgado na vigência da Constituição de 1934 só permitia a representação parlamentar aos grupos ou partidos: "Sómente poderão concorrer às eleições candidatos registrados por partidos ou alianças de partidos, ou mediante requerimento de eleitores: 50, nas eleições municipais, 200 nas estaduais ou federais" (Art. 84, da lei n. 48, de 4, de maio de 1935). 
monstram as teorias modernas do abuso de direito, da imprevisão (cláusula rebus sic stantibus), do risco profissional, da guarda, etc. (22). Vê-se, portanto, que em relação a eles, o direito social seria antes "a adatação da forma jurídica à realidade social em virtude da consideração do homem concreto e socializado", no lugar do indivíduo abstratamente considerado.

Isto não obsta, entretanto, a que esse movimento de renovação das normas jurídicas tenha progredido mais num determinado ramo do direito, o das relações entre os economicamente fortes e os economicamente fracos, e da competente intervenção do Estado nessas relações, produzindo dois ramos do Direito, inteiramente autônomos: o Direito Econômico e o Direito Social propriamente dito, ou Direito Social stricto sensu, que RADBRUch chama Direito Operário.

O primeiro, segundo ele, "ainda no estado de programa e fragmento" consiste na regulamentação jurídica dos carteis, na proteção dos locatários, na restrição das possibilidades deixadas ao patrão de parar o trabalho, nas obrigações de construir, de modo que: "lá, onde, no interesse da Sociedade, o Estado intervem nas relações de direito privado para regularizar e organizar, ha direito econômico", que vem a ser assim, na frase de Goldschmid, "o direito próprio da economia organizada". Já havíamos, em trabalho anterior, salientado este aspeto do Direito Econômico: "O Direito Social só cogita da hipossuficiência, ou debilidade econômica absoluta, que é a definida por nós acima. A debilidade econômica rolativa, isto é, o fato de ser apenas um ser economicamente mais fraco do que um outro, é objeto, não do Direito Social, mas do Direito Econômico, v. g., a posição do pequeno capitalista ou do pequeno industrial, em frente ao grande capitalista ou ao grande industrial, etc." (23).

(22) Cf. "A Regra Moral nas Obrigações Jurídicas" (trad. Osorio de Oliveira), São Paulo, 1937, pgs. 408 e 409.

(23) “Direito Social Brasileiro", pg. 26, nota 31. 
O segundo, feito para proteger os individuos socialmente fracos, deve ser definido como nós o fizemos. Alérn dos autores por nós já citados, ao darmos a nossa definição, concordam com ela: ReNARd que, ao citar a revista francesa "Droit Social", diz que ela "consigne et commente, avec une profonde objetivité, les documents de ce qu'on est convenu d'appeler le "droit social": textes de lois, réglements, sentences arbitrales, conventions collectives, projets parlamentaires, propositions émanant des organisations sindicales" (24); ERnest Freund: "By the term social legislation we understand those measures which are intended for the relief and elevation of the less favored classes of the Community" (25); Waldemar Ferreira: "Leis sociais são leis de proteção, destinadas a atender a situações econômicas de pessoas que se encontrem no plano comum das mesmas necessidades"; (26) na magnífica "Encyclopedia of the Social Sciences", dirigida por Seligman, Edwin E. Witre, afirma: "Social legislation is a narrower concept than social and political reform but broader than labor legislation. Labor legislation wheter in the form of statutes, administrative orders or judicial decisions is specifically concerned with regulating conditions of labor and relation between employers and employees. Social legislation includes also such fields as poor relief, public education and housing, only minor features can be included within the concept of labor legislation" (27).

Isto posto, examinemos, mais detidamente, as críticas à nossa definição. O Pe. SAbóIA DE Medeiros nos argue de não definirmos todo o direito social. Neste ponto tem evidentemente razão, conforme já reconhecemos. Nós quisemos definir apenas o Direito Social stricto sensu, que é o que

(24) Cit. "La Philosophie de l'Institution", pg. 6.

(25) Apud Castro Nunes, "Da Justiça do Trabalho no Mecanismo Jurisdicional do Regime", in "Boletim do Ministerio do Trabalho", 1937, 30/89.

(26) "A Justiça do Trabalho", São Paulo, 1938, I/27.

(27) Edição de 1937, vol. 4, pg. 658, vb. "Labor Legislation and Law". 
se convencionou chamar Direito Social (28). Outra objeção afirma que: "Si o direito social vai diretamente ao indivíduo e à sua família, qual é o direito que visa os grupos profissionais e culturais?" A proteção dispensada pelas leis sociais visa, diretamente os indivíduos e suas famílias, mas é claro que compreenderá tudo o que seja necessário ao cumprimento dessa sua finalidade. Não sustenta a doutrina social católica que só o indivíduo é fim, e a sociedade, meio para a consecução dos fins do indivíduo? Logo, sendo os grupos profissionais e culturais meios necessários para que os indivíduos satisfaçam as suas necessidades vitais, entre as quais se incluem as profissionais e culturais, é evidente que naquela proteção estão implicitamente contidas estas. Quanto ao fato de saber: "em que ponto a hipossuficiência de relativa passa a absoluta", que é exatamente o ponto distintivo entre o Direito Social e o Direito Econômico, insistiremos sobre a nossa afirmação de que a hipossuficiência absoluta se carateriza pelo fato do indivíduo depender do produto do seu trabalho para manter-se e à sua família. Logo, uma vez que o indivíduo possua rendimentos que lhe assegurem essa subsistência, independentemente do seu trabalho, cessa a hipossuficiência absoluta, começando a relativa sempre que um comerciante, um industrial, um lavrador, um capitalista, um proprietário enfim (porque todos os autossuficientes são proprietários de mercadorias, maquinismos, terras, dinheiro e outros valores, etc.) estiver em situação de dependência em relação a

(28) E' digno de nota que alguns Tribunais de Apelação têm dado à expressão legislação social, contida nos arts. 112 da Constituição de 1934, e 139, da Constituição de 1937, uma acepção mais restrita, apenas compreensiva das "chamadas leis trabalhistas", o que nos parece de todo ponto inexato (Cf. "Revista Forense", 82/115). Em acordão de 1 de dezembro de 1939 do Tribunal de Apelação do Distrito Federal se lề o seguinte: "O Tribunal de Apelação, em sessão plena de julgamento de prejulgado, realizada em 14 de dezembro do ano proximo findo, decidiu que nos conflitos entre empregados e empregadores as Juntas de Conciliação e Julgamento só poderão aplicar as leis trabalhistas, sendo incompetentes para aplicar dispositivos de direito comum (no caso o art. 81 do Código Comercial)". (Cit. "Revista", 82/334). Já dissemos que não seguimos essa opinião (Cf. "Direito Social Brasileiro", pg. 303). 
outro proprietário socialmente mais forte do que ele. Não é exáto que hajamos firmado "não haver outro direito social senão o emanado do Estado", o que nos levaria "bem perto do Estado totalitário e da concepção política das corporações". Muito pelo contrário, não sómente em nossa definição falamos simplesmente em "princípios e normas" sem investigar-lhes a origem, estatal ou não estatal, como, ao esquematizarmos a matéria, distinguimos a autoproteção, resultante da união dos economicamente fracos, da heteroproteção, a eles dispensada pelo Estado (29). E, assim sendo, ficam prejudicadas as objeções de que: "si ha hipossuficiência não ha autoproteção; si ha autoproteção não ha hipossuficiência; dizer que a união faz a fôrça é conceder: 1) que ha princípios e normas jurídicas independentes do Estado; 2) e, quando a união é corporativa, que ha um direito social, o qual visa não só os empregados hipossuficientes, mas os empregados suficientes". Não temos dúvida em fazer essas concessões, mesmo porque... elas não representam concessão alguma. Com efeito, já havíamos afirmado: "Esquematizando, poderíamos dizer que, em última análise, o Direito Social é "o sistema legal de proteção aos economicamente fracos". Esta proteção póde consistir numa auto-proteção, quando nesulta principalmente da união, da organização desses indivíduos : é o caso do Direito Corporativo; ou numa heteroproteção, quando resulta precipuamènte da ação do Estado, embora em certos casos com pequena participação dos hipossuficientes" (30). Aliás, a própria participação dos autossuficientes no Direito Social é evidente: si este contém normas de proteção, é

(29) Cf. "Direito Social Brasileiro", pg. 27. Cf. tambem o esquema da pg. 33. E' evidente que o fato de falarmos aí em "sistema legal de proteção aos hipossuficientes", atendeu apenas a uma necessidade de abreviar a nossa definição, tendo em vista as conveniências do citado esquema, mas não significa considerar o direito social de origem meramente estatal. Isto não obstante, nos reportamos à citação acima de Sinzheimer, segundo o qual o Estado "intervient dans le droit non étatique pour l'impregner d'élements formels".

(30) “Direito Social Brasileiro", pg. 31. 
evidente que essa proteção deve ser exercida em relação a alguem, no caso os autossuficientes, conforme já haviamos frisado: "Logo, só se devem excluir do campo do Direito Social, como protegidos por ele (como "protegidos", note-se bem, por isso que, sob outros aspetos, v. g., como "empregadores", eles entram no seu campo de aplicação), os indivíduos economicamente fortes, ou sejam os "remediados e os ricos", os "autossuficientes", em suma". (31)

Igualmente não me parecem procedentes as objeções do Dr. VASco DE ANDrade. Significam elas que pretendemos fazer do Direito Social um Direito de classe, um "código dos pobres", em oposição ao Código Civil, que foi chamado o "código dos ricos". Prevendo essa objeção já havíamos dito: "Mas, então — dir-se-á — o Direito Social é um direito de classe, um privilégio, e como tal injusto. Nada menos certo. O fim imediato das leis sociais é a proteção aos fracos, concordamos. Mas, não é o único. Por intermédio dessa proteção o que o Estado realmente visa é assegurar a paz social, o interesse geral, o bem comum" (32). E ninguem poderá negar que, estabelecendo a paz social, pela proteção que dispensa ao pobre, o Direito Social está do mesmo passo protegendo o rico, pois enquanto garante a subsistência de um, assegura a tranquilidade de outro.

Assim respondidas as principais objeções à nossa definição de Direito Social, passemos a examinar as definições propostas por outros membros do Instituto de Direito Social. Assim, o Pe. Sabóia de Medeiros propõe a seguinte: "Definiriamos, pois, o direito social, si se requeresse uma definição: "as regalias e as normas naturais ou positivas, que regem os grupos no seio da sociedade perfeita, adatando os membros aos grupos, e ao mesmo tempo as relações destes entre si e com a sociedade perfeita". Parece-nos uma definição por demais... escolástica. Não compreendemos o que em ciência jurídica se entenderia por "regalias". Ademais, a preocupação com os "grupos" exclusiva-

(31) Ob. cit., pgs. 20 e 21 .

(32) Ob. cit., pg. 19. 
mente dá antes idéia de que se define o Direito Corporativo, que é apenas uma parte do Direito Social. Si o P. SAbóra via em nossa definição excessivo estatismo, poderiamos dizer que na sua ha exatamente o contrário. Como classificar o Direito do Trabalho, abstração feita das "regalias", entre "as normas que regem os grupos"? Será na "adatação dos membros aos grupos"? Não nos parece nada claro.

O Dr. Vasco de ANDRAde define: "Direito Social - relações dos grupos e dos indivíduos que os compõem, enquanto membros, tendo em vista o bem comum particular". Nova definição mais própria para o Direito Corporativo, parecendo convir, além disto, a vários outros ramos do Direito. Não seria lícito incluirem-se nela todas as relações sociais, inclusive as das sociedades civis comuns, das sociedades comerciais, etc.?

Em trabalho apresentado ao I Congresso Brasileiro de Direito Social (32-a), o Dr. RuY SODRÉ, infatigavel secretáriogeral do Instituto de Direito Social, apresenta a seguinte definição: "O direito social, tomando como ponto de partida o indivíduo como pessoa humana, visa a harmonização do individual e do social, regulando as relações dos indivíduos singularmente considerados e os grupos a que os mesmos pertencem, colimando o bem comum" Ha nesta definição uma consideração verdadeira; a da "pessoa humana", que se deve entender como a "pessoa concreta e socializada", de que nos fala Radbruch. Prejudica, porém, a definição, a preocupação já notada nas anteriores com os "grupos". Desnecessária nos parece a referência ao bem comum, que só incluimos em nossa definição, para evitar a acusação de ser ela unilateral, direito de classe, por isto que o "bem comum" está compreendido na própria noção de direito, de lei. (33)

(32a) Direito Social, seu conceito filosófico, sociológico e juridico, conteudo e definição, in "Conceito e Conteudo do Direito Social", publicação do "Instituto de Direito Social", vol. II, n. II de maio de 1941, pgs. 53 a 82.

(33) Lex est ordinatio rationis, ad bonum commune, ab eo qui curam habet communitatis, promulgata. 
O P. Eduardo Lustosa propôs a seguinte: "Direito Social é a ciência das relações de justiça distributiva e legal no terreno da profissão (sobretudo da profissão econômica ou debaixo do ponto de vista econômico)". Sôbre incluir elementos não estritamente jurídicos e simples (justiça legal e distributiva), essa definição não atende aos caracteres que apontamos para o direito social, e encara sómente o aspeto da profissão, quando ha outros aspetos interessantes, mas extra-profissionais, como a proteção à família, à velhice, etc.

O Dr. Sousa Neto define: "O complexo de normas (princípios e leis) que tendem a estabelecer o equilíbrio nas relações dos membros (individuais ou coletivos) das formações sociais (agrupamentos organizados - "sociedades imperfeitas" - e agrupamentos inorganizados), considerados como tais". Sempre a preocupação do grupo e o esquecimento total do indivíduo, não obstante a citada afirmação da doutrina social católica de que sómente o individuo é fim e a sociedade meio.

Por sua vez o Dr. Carvalho Borges define o Direito Social, como "um conjunto de princípios ou normas que regem os fenômenos de colaboração: entre indivíduos, entre grupos, entre indivíduos e grupos". Temos a impressão de que, si nós nos deixamos levar pelo Direito do Trabalho, como afirma o Dr. VAsco DE ANDrade, os nossos distintos confrades se deixaram levar pelo Direito Corporativo. E' o que se nota nesta definição: o carater de colaboração é próprio do Direito Corporativo, como notam, principalmente todos os autores italianos modernos; da mesma fórma, a preocupação exclusiva com os "grupos".

Finalmente, "the last, but not the least", o Dr. Fernando Callage considera o Direito Social, "como aquele que visa estabelecer a harmonia entre as classes sociais". Estamos de acôrdo com esta definição, que, apenas, nos parece carecer de maior precisão.

Incumbido de procurar uma conciliação entre essas opiniões, o PE. Eduardo Lustosa propôs a seguinte definição: 
"Direito Social é o complexo de princípios e normas que têm por objeto a realização da justiça nas relações dos grupos sociais, naturais ou artificiais, organizados ou não, do ponto de vista da solidariedade das pessoas humanas". Pensamos que não oferece precisão científica, por incluir vários termos passiveis de controvérsia quanto ao seu verdadeiro significado ("justiça", "solidariedade", etc.), além de não apresentar os verdadeiros caracteres do Direito Social, embora já faça referência à pessoa humana.

Julgamos que seria mais exata e atenderia a todas as correntes esta outra, que propomos à consideração do Instituto de Direito Social: "Direito Social é o complexo de princípios e normas imperativas que têm por objeto a adatação da fórma jurídica à realidade social, mediante a consideração do homem na sua individualidade concreta e socializada e, precipuamente, a proteção aos indivíduos dependentes do produto de seu trabalho para a subsistência sua e de suas famílias"; ou esta outra, idêntica no fundo, embora diversa na fórma:

"Direito Social é o complexo dos principios 1 . normas imperativas que têm por objeto a adiatação da forma jurídica à realidade social, considerando os homens na sua individualidade concreta e como membros dos grupos sociais diferentes ido Estado, e tendo em vista, principalmente, as diferenças de situação econômica entre eles existentes". ( $\left.{ }^{\star}\right)$

Parece-nos justo ressaltar este aspeto econômico do Direito Social, com o qual concordou, aliás, o PE. Eduardo LusTosA, por isso que desconhecer ser ele oriundo da revolução econômica, iniciada no século passado, é negar a própria luz do sol.

(*) Cf. esta definição do Direito Social Generico, ou Direito Social lato sensu, com a definição adotada recentemente pelo 1 Congresso Brasileiro de Direito Social: "Direito Social, lato sensu, é o complexo de princípios e normas imperativas, que têm por sujeito os grupos e respectivos membros, e por objeto, a adaptação da fórma jurídica à realidade social, visando a colaboração de todos para o bem comum". 